\title{
Alcohol causes hypoglycaemic unawareness in healthy volunteers and patients with Type 1 (insulin-dependent) diabetes
}

\author{
D. Kerr ${ }^{1}$, I. A. Macdonald ${ }^{2}$, S. R. Heller ${ }^{1}$ and R. B. Tattersall ${ }^{1}$ \\ Departments of ${ }^{1}$ Medicine and ${ }^{2}$ Physiology and Pharmacology, University Hospital and Medical School, Nottingham, UK
}

\begin{abstract}
Summary. Both hypoglycaemia and alcohol consumption affect cognitive function but it is unclear whether moderate drinking alters awareness of hypoglycaemia. We have examined this in a single blind randomised hyperinsulinaemic clamp study in eight non-diabetic subjects and seven Type 1 (insulin-dependent) diabetic patients. After $30 \mathrm{~min}$ of euglycaemia (blood glucose $4.5 \mathrm{mmol} / \mathrm{l}$ ) subjects drank either $0.75 \mathrm{~g} / \mathrm{kg}$ ethanol or a placebo drink after which blood glucose was lowered to $2.5 \mathrm{mmol} / \mathrm{l}$ for $40 \mathrm{~min}$. Awareness of hypoglycaemia, reaction time and physiological responses were measured before and after ethanol. At a blood glucose concentration of $4.5 \mathrm{mmol} / 1$, ethanol (producing peak blood levels of $20-25 \mathrm{mmol} / \mathrm{l})$ caused a transient increase in systolic blood pressure $(p<0.05)$, a sustained increase in heart rate $(p<0.01)$ and a slowing of reaction time in both normal sub-
\end{abstract}

jects and diabetic patients. During hypoglycaemia in both groups, the slowing of reaction time and increase in sweating were more marked after ethanol than placebo (both $p<0.05)$, while the increase in finger tremor $(p<0.05)$ was blunted after ethanol, in both groups. Counter regulatory hormone secretion was not affected by ethanol. Despite increases in symptoms during hypoglycaemia, only 2 of 15 individuals "felt hypoglycaemic" after ethanol compared to 11 out of 15 after placebo. We conclude that after moderate drinking non-diabetic subjects and Type 1 diabetic patients are less aware of hypoglycaemia despite exaggerated physiological changes.

Key words: Alcohol, hypoglycaemia, cognitive function, counter-regulation, hypoglycaemic awareness.
It has been recommended that insulin treated diabetic patients should be cautious when drinking alcohol because symptoms of hypoglycaemia may be obscured or modified by the cerebral effects of ethanol [1] although we know of no experimental evidence upon which this is based. In addition, ethanol itself causes significant cardiovascular changes [2] and may affect the release of hormones involved in glucose counter-regulation [3]. Therefore, the cerebral effects of ethanol or its modification of peripheral physiological changes might adversely affect awareness of hypoglycaemia although this has only been tested in rats where Sammalisto [4] showed that hyperglycaemia tempered intoxication while hypoglycaemia enhanced it.

Our aim was to examine the effects of moderate drinking on awareness of, and the physiological and hormonal counter-regulatory responses to, hypoglycaemia in nondiabetic subjects and patients with Type 1 (insulin-dependent) diabetes mellitus.

\section{Subjects and methods}

Seven men with Type 1 diabetes (Table 1 ) and eight non-diabetic subjects (six female) were recruited. Apart from insulin no subject was taking any medication except the oral contraceptive pill (three non-diabetic subjects). Patients were selected on their willingness to participate and on the basis of stable, well controlled diabetes (three previous glycosylated haemoglobin levels less than $10 \%$ ). No patient had clinical evidence of autonomic or peripheral neuropathy, or albuminuria but one had background retinopathy. None had a history of hypoglycaemic unawareness. All patients and volunteers drank less than 15 units of ethanol per week ( 1 unit = half pint of beer or $23 \mathrm{ml}$ of spirits). Written consent was obtained for the study which was approved by the hospital and medical school ethical committees. Two studies were performed on each subject at least 2 weeks apart.

\section{Glucose clamp}

At 08.00 hours on the morning of the experiment, the diabetic patients were admitted fasting to the metabolic unit having had their last insulin the previous evening. Blood glucose was kept between 
Table 1. Clinical characteristics of patients with diabetes

\begin{tabular}{lllllll}
\hline Patient & $\begin{array}{l}\text { Age } \\
\text { (years) }\end{array}$ & $\begin{array}{l}\text { Sex } \\
\text { Duration } \\
\text { diabetes } \\
\text { (years) }\end{array}$ & $\begin{array}{l}\mathrm{HbA}_{1} \\
\%\end{array}$ & $\begin{array}{l}\mathrm{BM} \mathrm{I} \\
\mathrm{kg} / \mathrm{m}^{2}\end{array}$ & $\begin{array}{l}\text { Compli- } \\
\text { cations }\end{array}$ \\
\hline 1 & 21 & $\mathrm{M}$ & 5 & 8.7 & 21.9 & None \\
2 & 35 & $\mathrm{M}$ & 23 & 8.0 & 28.1 & $\begin{array}{l}\text { Retino- } \\
\text { pathy }\end{array}$ \\
3 & 23 & $\mathrm{M}$ & 3 & 8.7 & 29.7 & None \\
4 & 19 & $\mathrm{M}$ & 5 & 9.9 & 21.2 & None \\
5 & 25 & $\mathrm{M}$ & 4 & 7.2 & 23.2 & None \\
6 & 37 & $\mathrm{M}$ & 5 & 7.6 & 23.9 & None \\
7 & 32 & $\mathrm{M}$ & 4 & 7.1 & 22.2 & None \\
\hline
\end{tabular}

$\mathrm{HbA}_{1}$ normal range $<7.5 \%$. Healthy volunteers Age $22-26$ years, 6 female

4.5 and $6 \mathrm{mmol} / \mathrm{l}$ by a continuous infusion of soluble insulin adjusted on the basis of measurements of blood glucose every $10 \mathrm{~min}$. Studies in the diabetic patients were deferred if venous blood glucose fell below $3.5 \mathrm{mmol} / 1$ during this period. The non-diabetic subjects fasted for $6-8 \mathrm{~h}$ before the study.

All experiments began at 13.00 hours when under local anaesthetic a cannula was placed in the non-dominant arm for infusion of human Actrapid insulin (Novo Laboratories, Copenhagen, Denmark) at a fixed rate of $60 \mathrm{mU} \cdot \mathrm{m}^{-2} \cdot \mathrm{min}^{-1}$ and a variable infusion of $20 \%$ dextrose. A modified hyperinsulinaemic glucose clamp [5] was used to maintain blood glucose at pre-determined levels. Arterialized venous blood samples were obtained from a cannula in a dorsal hand vein of the same arm; the hand was placed in a heated box $\left(55-60^{\circ} \mathrm{C}\right)$ and the cannula kept patent by a $154 \mathrm{mmol} / 1 \mathrm{NaCl}$ infusion. Glucose was administered by an IVAC 560 pump (IVAC, San Diego, Calf., USA) adjusted every 2.5 min according to blood glucose measured at the bedside with a glucose oxidase method (Yellow Springs Instrument, Yellow Springs, Ohio, USA).

Subjects had blood glucose clamped at $4.5 \mathrm{mmol} / \mathrm{l}$ for $60 \mathrm{~min}$. After $30 \mathrm{~min}$ at this blood glucose level, they drank $0.75 \mathrm{~g}$ of pure ethanol per $\mathrm{kg}$ body weight (equivalent to 2 or 3 large measures of vodka) diluted with twice the volume of low calorie fruit squash (ethanol study) or on another occasion they had the diluent only (placebo study). The order of experiments was randomised between subjects and, although they were "blind", most recognised which drink contained alcohol. After this $60 \mathrm{~min}$ period of euglycaemia, blood glucose was lowered by varying the glucose infusion rate to $2.5 \mathrm{mmol} / \mathrm{l}$ and held there for a further $40 \mathrm{~min}$. The insulin infusion was then discontinued and blood glucose allowed to recover. In the non-diabetic study further arterialised venous blood samples were taken 15 and 30 min after the insulin infusion for measurement of counter-regulatory hormones.

All non-diabetic subjects had the likely symptoms of hypoglycaemia explained before each experiment. All subjects knew that blood glucose would be lowered at some time during each experiment, but did not know when.

\section{Physiological measurements}

Heart rate and blood pressure were measured by an automated oscillometric method (Accutor 1A monitor, Datascope Corp, NJ, USA). Rates of sweating were measured over the lower sternum with a ventilated capsule using dew-point sensors (Michell Instruments, Cambridge, UK) to estimate the water content of inflowing and outflowing air [6]. Finger tremor was measured by an accelerometer (Bruel and Kjaer 4367) connected by a "Perspex" ring to the terminal phalanx of the middle finger of the dominant hand. Measurements were made for $1 \mathrm{~min}$, with the forearm supported and hand outstretched as previously described [7].

Awareness of hypoglycaemia was assessed by asking the general question "do you feel hypoglycaemic?" A symptom score was obtained by asking subjects to rate seven symptoms as absent, mild, moderate or severe (scored 0, 1,2 or 4 respectively). The symptoms were facial flushing, tingling of the fingers or around the lips, trembling, palpitations, sweating, blurred vision and sleepiness. Dummy questions (not scored) were asked to make sure that the subjects were not answering "automatically" because of neuroglycopoenia. A $100 \mathrm{~mm}$ visual analogue scale was used to assess whether subjects knew their blood glucose level, the extremes of the scale being defined as "blood glucose normal" and "blood glucose very low". In addition another $100 \mathrm{~mm}$ visual analogue scale was used to assess sobriety; the extremes of this scale were "sober" and "drunk". Assessments of awareness of hypoglycaemia and sobriety, and physiological measurements were made twice at a blood glucose of $4.5 \mathrm{mmol} / \mathrm{l}$

Table 2. Mean (SEM) blood glucose, plasma free insulin and blood alcohol levels during the healthy volunteer and patient studies

\begin{tabular}{lllll}
\hline & \multicolumn{2}{l}{ Time (min) } & 90 & 120 \\
\cline { 2 - 4 } & 30 & 60 & $2.43(0.03)$ & $2.53(0.06)$ \\
\hline $\begin{array}{l}\text { Healthy volunteer study } \\
\text { Placebo }\end{array}$ Glucose (mmol/) & $4.44(0.07)$ & $4.43(0.04)$ & $2.48(0.02)$ & $2.53(0.04)$ \\
Alcohol & $4.44(0.09)$ & $4.54(0.05)$ & $20.14(0.9)$ & $18.49(0.4)$ \\
Alcohol (mmol/1) & $0.19(0.1)$ & $18.31(2.1)$ & $110.5(13.7)$ & $108.5(13.2)$ \\
Placebo & $86.41(4.1)$ & $109.8(12.1)$ & $113.3(11.5)$ & $116.8(10.6)$ \\
Insulin (mU/l) & $117.6(23.6)$ & $110.6(9.1)$ & & \\
Alcohol & & & $2.44(0.03)$ & $2.50(0.06)$ \\
Patient study & $4.42(0.08)$ & $4.44(0.05)$ & $2.47(0.04)$ & $2.52(0.03)$ \\
Placebo & $4.43(0.09)$ & $4.50(0.06)$ & $23.8(1.4)$ & $22.2(0.7)$ \\
Glucose (mmol/l) & $1.39(0.5)$ & $16.8(1.1)$ & $118.7(11.7)$ & $125.3(16.2)$ \\
Alcohol & $89.5(28.4)$ & $102.5(21.2)$ & $117.0(22.7)$ & $142.3(26.6)$ \\
Alcohol (mmol/1) & $129.7(35.0)$ & $115.6(19.8)$ & & \\
Placebo & & & & \\
Insulin (mU/l) & Alcohol & &
\end{tabular}



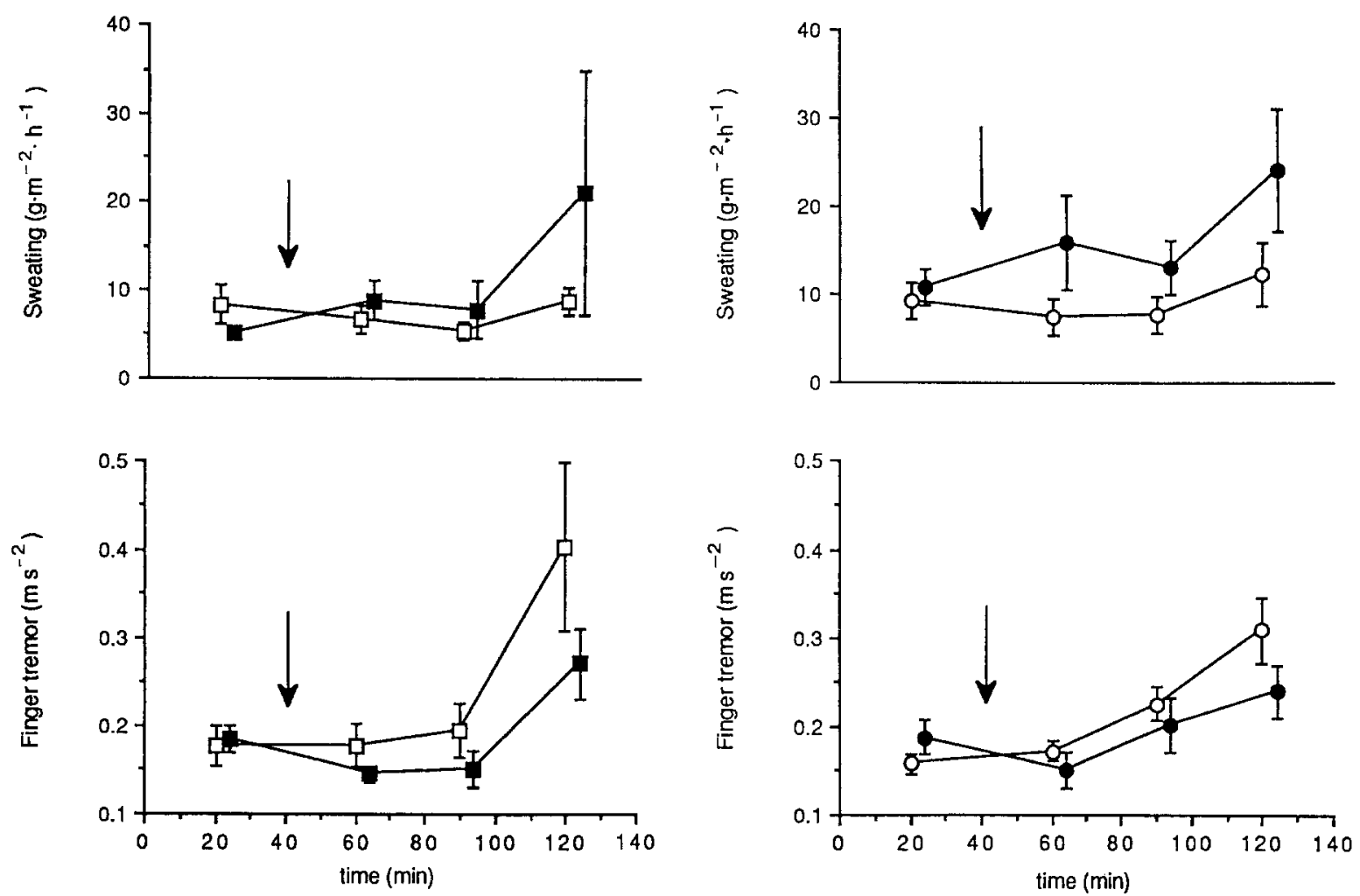

Fig. 1. Sweat production and finger tremor before and after ethanol and during hypoglycaemia in the normal subject (left hand side) and patient (right hand side) studies. Two-way analysis of variance showed that ethanol augmented sweat production and diminished

(before and after ethanol or placebo), and after 10 and 40 min at $2.5 \mathrm{mmol} / \mathrm{l}$.

Cognitive function was assessed with a four-choice reaction timer [8] over $5 \mathrm{~min}$ periods, at baseline (blood glucose $4.5 \mathrm{mmol} / \mathrm{l}$ ), after ethanol or placebo, and during hypoglycaemia (blood glucose $2.5 \mathrm{mmol} / \mathrm{l}$ ). In this test subjects depress a microswitch corresponding to one of four flashing lights which automatically come on and off in a random order. The latency period is recorded on cassette tape for subsequent computer analysis.

\section{Counter-regulatory hormones}

After each reaction time measurement during euglycaemia, after 10 and 40 min during hypoglycaemia, and 15 and 30 min after stopping the insulin infusion (non-diabetic study only), blood was taken from the heated hand vein, centrifuged at $4^{\circ} \mathrm{C}$ and $2000 \mathrm{~g}$ for $10 \mathrm{~min}$ and the plasma added to tubes containing $75 \mu \mathrm{l}$ of EGTA-glutathione for measurement of catecholamines, $75 \mu \mathrm{l}$ of Trasylol (Bayer UK Ltd, Newbury, Berks., UK) for glucagon and pancreatic polypeptide, and into plain tubes for growth hormone and cortisol. The plasma for measurement of free insulin was extracted by adding equal volumes of a polyethylene glycol/phosphate buffer mixture, vortexed and spun for $30 \mathrm{~min}$ to remove the precipitated globulin fraction [9]. All samples were stored at $-80^{\circ} \mathrm{C}$ and all samples from a single subject were analysed at the same time. Adrenaline and noradrenaline were measured by high performance liquid chromatography with electrochemical detection [10]. Cortisol and growth hormone were measured by an in-house direct radioimmunoassay. Free insulin [9], pancreatic polypeptide [11] and glucagon [12] were measured by radioimmunoassay. Intraassay coefficients of variation were; glucagon $11.1 \%$, adrenaline $6 \%$, noradrenaline $4 \%$, growth hormone $6.8 \%$, cortisol $6 \%$ and free insulin $9 \%$. finger tremor in both studies (both $p<0.05$ ). $\downarrow$ ethanol or placebo given. Normal subjects: placebo $\square$; alcohol $\square$. Diabetic patients: placebo $O$; alcohol

\section{Statistical analysis}

Results are expressed as mean (SEM). Where appropriate, data were logarithmically transformed before two-way and one-way analysis of variance, corrected for repeated measures with Duncans range test. When two-way analysis of variance indicated significant treatment by time interactions, the nature of these differences was determined by paired $t$-tests on the contrasts in group means.

\section{Results}

Blood glucose, ethanol and plasma insulin. Mean blood glucose, plasma insulin and blood ethanol levels during each study are shown in Table 2 . Peak blood ethanol levels were greater in the patients $(23.8 \pm 1.4 \mathrm{mmol} / \mathrm{l})$ than nondiabetic subjects $(20.1 \pm 0.9 \mathrm{mmol} / \mathrm{l} p<0.05)$. Five subjects had ethanol first but all correctly identified the ethanol study as shown by movement towards the "drunk" end of the visual analogue scale.

\section{Non-diabetic subjects}

Heart rate, blood pressure, finger tremor and sweating. Consumption of ethanol was accompanied by an increase in heart rate during euglycaemia (from $70.1 \pm 3.2$ to $80.0 \pm 3.3 p<0.01$ ) which was sustained when blood glucose was lowered to $2.5 \mathrm{mmol} / 1$. In the placebo study heart rate increased only during hypoglycaemia (from 69.3 \pm 2.5 

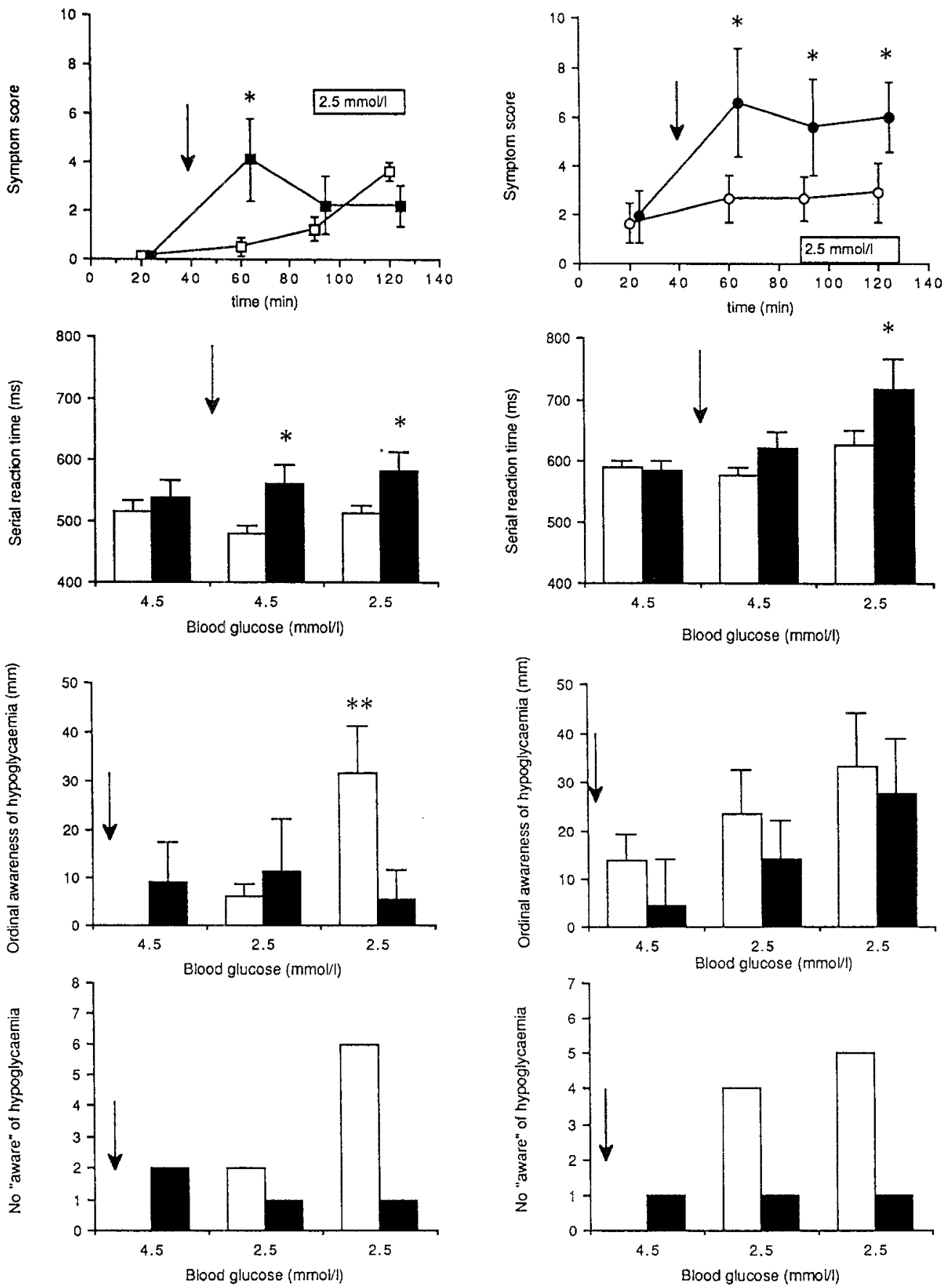
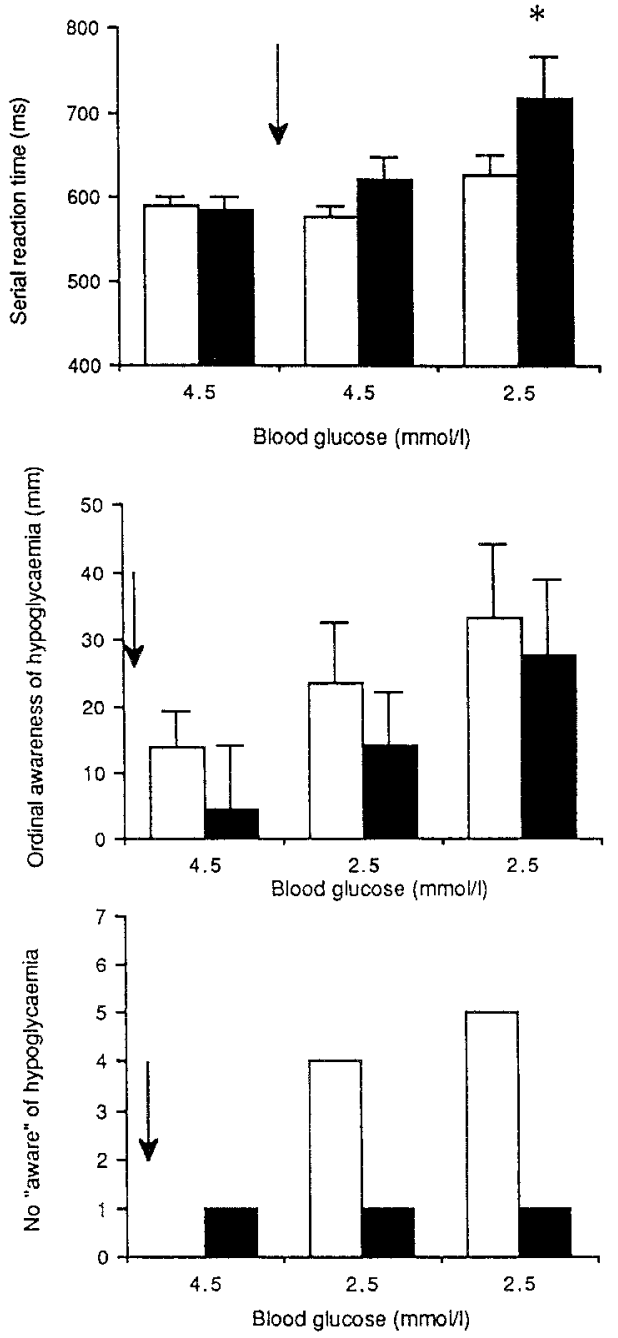

Fig. 2. Mean \pm SEM symptom scores, serial reaction time, ordinal awareness of hypoglycaemia (movement along $(\mathrm{mm})$ the visual analogue scale in the direction of 'blood sugar very low') and number of subjects aware of hypoglycaemia during the normal subject (left hand side) and patient (right hand side) studies. $\downarrow$ ethanol or placebo given. * $p<0.05$; *** $p<0.01$. alcohol, $\mathbf{\square}, \mathbf{\bullet}$ placebo $\square, O, \square$ to $75.8 \pm 3.3 p<0.01)$. After ethanol systolic blood pressure increased transiently (from $118.1 \pm 3.1$ to $123.0 \pm 1.4$ $p<0.05$ ) during euglycaemia but was not significantly different from baseline during hypoglycaemia or throughout the placebo experiment. Diastolic blood pressure fell during hypoglycaemia (from $65.8 \pm 2.1$ to $58.8 \pm 3.0, p<0.02$ ) only in the placebo study. The increase in finger tremor during hypoglycaemia was less marked after ethanol than after the placebo drink ( $p<0.05$ Fig. 1$)$. In contrast, during hypoglycaemia, sweating only increased significantly after ethanol ( $p<0.05$ Fig. 1$)$.

Pancreatic polypeptide and counter-regulatory hormone levels. Plasma adrenaline (placebo $1.70 \pm 0.30$, ethanol $1.55 \pm 0.30 \mathrm{nmol} / \mathrm{l}$ ), pancreatic polypeptide (placebo
$125 \pm 40$, ethanol $100 \pm 20 \mathrm{pmol} / 1)$, growth hormone (placebo $8 \pm 4$, ethanol $14 \pm 5 \mathrm{mU} / \mathrm{l}$ ) and glucagon (placebo $15 \pm 7$, ethanol $8 \pm 3 \mathrm{pmol} / \mathrm{l}$ ) rose to similar levels during hypoglycaemia on both occasions. Cortisol did not increase above baseline until the recovery period when it rose to $593 \pm 25 \mathrm{nmol} / 1$ (from $434 \pm 98 \mathrm{nmol} / 1$ ) after placebo and to $654 \pm 61 \mathrm{nmol} / 1$ (from $380 \pm 73 \mathrm{nmol} / \mathrm{l}$ ) after ethanol $(p<0.05), 30 \mathrm{~min}$ after the end of the insulin infusion.

Reaction time, symptom score and hypoglycaemic awareness (left panel of Fig. 2). Ethanol was associated with an increase in symptom score $(p<0.05)$ during euglycaemia. This was predominantly due to increased reporting of sweating, palpitations, facial flushing and blurred vision. The symptom score during hypoglycaemia was the same 
with and without ethanol. Baseline serial reaction times were similar but during euglycaemia reaction time was significantly slower after ethanol $(p<0.05)$ and the same was true during hypoglycaemia $(p<0.05)$.

When blood glucose was $4.5 \mathrm{mmol} / \mathrm{l}$, two normal subjects "felt hypoglycaemic" after ethanol. At $2.5 \mathrm{mmol} / \mathrm{l}$, six of the eight "felt hypoglycaemic" after the placebo drink but only one after ethanol. Awareness of a reduction in blood glucose as measure don the visual analogue scale (ordinal awareness) paralleled the actual change in blood glucose (Fig. 2) during the placebo study but not after ethanol.

\section{Diabetic patient study}

Heart rate, blood pressure, finger tremor and sweating. Two patients had ethanol first. During euglycaemia heart rate increased after ethanol (from $70.1 \pm 4.7$ to $77.4 \pm 3.4$, $p<0.01$ ) but was unchanged after the placebo drink. During hypoglycaemia heart rate increased from $68.7 \pm 3.6$ to $81.0 \pm 5.5,(p<0.01)$ in the placebo study and to $86.1 \pm 5.5$ after ethanol, $(p<0.01)$. During euglycaemia systolic blood pressure increased transiently (from $123.9 \pm 5.6$ to $135.4 \pm 4.8 \mathrm{mmHg}, p<0.05$ ) after ethanol but diastolic blood pressure was unchanged during both studies. During hypoglycaemia the increase in finger tremor was less marked after ethanol than after the placebo drink ( $p<0.05$ Fig. 1$)$. In contrast sweat production, during hypoglycaemia, was augmented by ethanol $(p<0.05$ Fig. 1$)$.

Pancreatic polypeptide and counter-regulatory hormone secretion. Plasma adrenaline (placebo $1.65 \pm 0.30$, ethanol $1.80 \pm 0.30 \mathrm{nmol} / \mathrm{l} p<0.01$ ) and growth hormone (placebo $15.5 \pm 4.5$, ethanol $13.5 \pm 4 \mathrm{mU} / 1 p<0.05$ ) levels were similar in both studies during hypoglycaemia. Pancreatic polypeptide increased above baseline to a similar extent in both studies in all patients (from $16.7 \pm 3.2$ to $28.6 \pm 5.4 \mathrm{pmol} / \mathrm{l}, p<0.05$ after the placebo drink and from $18.4 \pm 3.4$ to $46.0 \pm 21.6 \mathrm{pmol} / \mathrm{l}, p<0.05$ after ethanol) but the increase was less than that in the non-diabetic subjects. Cortisol and glucagon did not change significantly in either study. Ethanol had no effect on hormone secretion at any stage. No measurements were made during the recovery phase.

Serial reaction time, symptom score and hypoglycaemic awareness (right panel of Fig.2). At a blood glucose of $4.5 \mathrm{mmol} / \mathrm{l}$ drinking ethanol was associated with an increase in symptom score $(p<0.01)$ predominantly due to increased sweating, palpitations, facial flushing and blurred vision, which was sustained during hypoglycaemia. Symptom score did not change significantly in the placebo study.

Baseline reaction times were similar but the slowing during hypoglycaemia was more marked after ethanol $(p<0.05)$.

When blood glucose was $4.5 \mathrm{mmol} / 1$, one patient "felt hypoglycaemic" after ethanol. At $2.5 \mathrm{mmol} / 1$ the visual analogue measurements paralleled the reduction in blood glucose and were not significantly affected by ethanol. However, only one subject "felt hypoglycaemic" at this stage after ethanol compared tofive after the placebo drink.

\section{Discussion}

Books and pamphlets given to patients with diabetes contain conflicting and often inadequate advice about the risks of alcohol [13]. They vary in their information about daily intake (ranging from "moderate quantities" to "ask the dietician"), and some contain no advice about the risks of hypoglycaemia after drinking alcohol. The British Diabetic Association recommend that an average of three drinks per day on a regular basis is the maximum (where one drink is defined as half a pint of beer or $23 \mathrm{ml}$ of spirits) and that it is better to drink less since moderate consumption may mask some of the warning symptoms of hypoglycaemia [14]. The blood alcohol concentration in this study (20-25 mmol/1) is just above the legal limit for driving in the United Kingdom and is associated with feelings of mental relaxation, a decrease in fine skills and a reduction in the ability to respond and perform. Nevertheless, at this level an individual is likely "to consider him/herself more alert and more capable than normal even though there has been a slowing of reaction time, judgment and the ability to respond to emergencies" [15].

We found that during hypoglycaemia, moderate alcohol intoxication decreased awareness, blunted finger tremor and increased reaction time and sweating in both diabetic patients and non-diabetic subjects without affecting the hormonal counter-regulatory response. Despite being aware of facial flushing, blurred vision, palpitations and sweating, only 2 of 15 subjects "felt hypoglycaemic" after alcohol compared with 11 of 15 in the control experiment when blood glucose was $2.5 \mathrm{mmol} / \mathrm{l}$. In addition, two non-diabetic subjects andone patient "felt" hypoglycaemic afteralcohol when blood glucose was normal. One explanation for the lack of awareness is that cognitive impairment (asshown by the deterioration in reaction time) wassogreat after alcohol as to prevent recognition of hypoglycaemia.

These studies highlight some of the problems inherent in examining hypoglycaemic (un)awareness in nondiabetic subjects. All the patients had stable glycaemic control prior to the study, thereby avoiding the influence of changing blood glucose thresholds for release of individual counter-regulatory hormones [16]. Despite the absence of a significant sweat response the diabetic patients still "felt hypoglycaemic" at a blood glucose of $2.5 \mathrm{mmol} / \mathrm{l}$, suggesting that patients rely on idiosyncratic cues rather than classical textbook warning symptoms. After alcohol the non-diabetic subjects could not recognise that their blood glucose was lower and did not "feel hypoglycaemic". In contrast the patients, who by definition had experienced hypoglycaemia before, knew that their blood glucose was lower but did not consider themselves hypoglycaemic i. e. they failed to appreciate the significance of a lower blood glucose and might therefore not have taken action. This is analogous to the person who denies being "over the limit" and feels capable of driving home, yet is obviously intoxicated to those around him.

We found no effect of alcohol on the hormonal counter-regulatory response, unlike Kolaczynski et al. [3] who reported that ethanol reduced growth hormone, cortisol and glucagon responses at blood glucose nadir of $2.3-2.5 \mathrm{mmol} / \mathrm{l}$. Their study involved only healthy men 
and used a larger dose of ethanol (mean oral and IV dose of $1.11 \mathrm{~g} / \mathrm{kg}$ body weight). Nevertheless in their study, blood glucose recovery was faster after alcohol despite the reduction in counter-regulatory hormone production, possibly due to peripheral insulin resistance. Earlier YkiJarvinen et al. [17] reported that peripheral glucose utilisation is reduced by prior administration of alcohol without any change in glucagon, growth hormone or cortisol levels under euglycaemic, hyperinsulinaemic conditions.

It is well known that alcohol affects the cardiovascular system. Most studies have shown an increase in heart rate $[2,18,19]$ probably as a reflex response to arteriolar or venous dilatation [20] and reduced circulating volume [21]. Our finding of a transient increase in systolic blood pressure after alcohol agrees with some $[2,19]$ but not all $[22,23]$ studies.

It has been known for many years that alcohol diminishes tremor [24] probably through a central mechanism since infusions of ethanol directly into the brachial artery of patients with essential tremor has no effect whereas ethanol given orally dramatically reduces tremor [25]. The enhancement of sweating duringhypoglycaemia afteralcoholmay have been the result of augmentation of the already increased sudomotor sympathetic nerve activity [26].

It has been suggested that "the usual symptoms of hypoglycaemia may be obscured or masked by the cerebral effects of alcohol" [27]. We found that moderate alcohol intoxication blunts hypoglycaemic awareness despite augmenting some of the physiological responses to a low blood glucose, but does not affect counter-regulatory hormone release. The information given to patients should be made clearer and contain more specific guidelines than are used at present. Finally, even though alcohol can cause hypoglycaemia, it should not be forgotten that low blood glucose can be mistaken for ethanol intoxication, with unfortunate social, economic as well as medical, consequencies for the patient [28].

Acknowledgements. We would like to thank Professor K.D.Buchanan, Belfast, for measuring plasma glucagon and pancreatic polypeptide, Mr. C.Selby of the City Hospital, Nottingham for measuring insulin, growth hormone and cortisol, Professor K. G.M.M. Alberti, Newcastle-upon-Tyne for measurement of plasma free insulin and Dr. M. Herbert for help with analysis of the serial reaction times. D. Kerr was supported by E. R. Squibb and Sons.

\section{References}

1. Krall LP, Entmacher PS, Drury TF (1985) Life cycle in diabetes: socioeconomic aspects. In: Marble A, Krall LP, Bradley RF, Christlieb AR, Soeldner JS (eds) Joslin's diabetes mellitus. Lea and Febiger, Philadelphia, pp 907-936

2. Stott DI, Ball SG, Inglis GC, Davies DL, Fraser R, Murray CD, McInness GT (1987) Effects of a single moderate dose of alcohol on blood pressure, heart rate and associated metabolic and endocrine changes. Clin Sci 73: 411-416

3. Kolaczynski JW, Ylikahri R, Harkonen M, Koivisto VA (1988) The acute effect of ethanol on counterregulatory response and recovery from insulin-induced hypoglycaemia. J Clin Endocrinol Metab 67: 384-388

4. Sammalisto L (1962) Blood sugar and alcohol intoxication in the rat. Acta Physiol Scand 55: 313-318

5. DeFronzo RA, Tobin JD, Andres R (1979) Glucose clamp technique: a method for quantifying insulin secretion and resistance. Am J Physiol 237: E214-E223
6. Wilcox RG, Bennett T, Macdonald IA, Herbert M, Skene AM (1984) The effects of acute or chronic ingestion of propranolol or metoprolol on the physiological responses to submaximal exercise in hypertensive men. Br J Clin Pharmacol 17: 273-281

7. Birmingham AT, Wharrad HJ, Williams EJ, Wilson CG (1985) Accelerometric measurements of finger tremor: analysis of the analogue signal. J Physiol (Lond) 361: 12P

8. Wilkinson RT, Houghton D (1975) Portable four-choice reaction time test with magnetic tape memory. Behav Res Meth Instrument 7: 441-444

9. Hanning I, Home PD, Alberti KGMM (1985) Measurement of free insulin concentrations: the influence of timing of extraction of insulin antibodies. Diabetologia 28: 831-835

10. Macdonald IA, Lake DM (1985) An improved technique for extracting catecholamines from body fluids. J Neuroscience Meth 13: $239-240$

11. O'Hare MMT, Daly JG, Buchanan KD (1983) Radioimmunoassay for pancreatic polypeptide and its age-related changes in concentration. Clin Chem 29: 1923-1927

12. Stout RW, Henry RW, Buchanan KD (1976) Triglyceride metabolism in acute starvation: the role of secretin and glucagon. Eur J Clin Invest 6: 179-185

13. Connor H (1987) Ethanol and diabetes-what should we tell our patients? Pract Diabetes 4: 159-160

14. Connor H, Marks V (1985) Alcohol and diabetes. Diab Med 2: $413-416$

15. Finn P, Platt J (1972) Alcohol and alcohol safety, a curriculum manual for senior high level: US Dept of Transportation, National Highway Traffic Safety Administration, Washington, DC. Vol 1, pp 178-187

16. Amiel SA, Sherwin RS, Simonson DC, Tamborlane WV (1988) Effect of intensive insulin therapy on glycemic thresholds for counter-regulatory hormone release. Diabetes 37:901-907

17. Yki-Jarvinen H, Nikkila E (1985) Ethanol decreases glucose utilisation in healthy man. J Clin Endocrinol Metab 61: 941-945

18. Ireland MA, Yandongen R, Davidson L, Beilin LJ, Rowe IL (1984) Acute effects of moderate alcohol consumption on blood pressure and plasma catecholamines. Clin Sci 66: 643-648

19. Potter JF, Macdonald IA, Beevers DG (1986) Alcohol raises blood pressure in hypertensive patients. J Hypertension 4: 435441

20. Altura BM, Altura BT (1983) Peripheral vascular actions of alcohol and its interaction with neurohumoral substances. Neurobehav Tox Teratol 5: 211-220

21. Child J, Kovick R, Levisman J, Pearce M (1979) Cardiac effects of acute ethanol ingestion unmasked by autonomic blockade. Circulation 59: 120-125

22. Riff D, Jain A, Doyle J (1969) Acute hemodynamic effects of ethanol on normal human volunteers. Am Heart J 78: 592-597

23. Kupari M (1983) Acute cardiovascular effects of ethanol. A controlled non-invasive study. Br Heart J 49: 174-182

24. Critchley M (1949) Observations on essential (heredo-familial) tremor. Brain 72: 113-139

25. Growdon JH, Shahani BT, Young RR (1975) The effect of alcohol on essential tremor. Neurology 25:259-262

26. Berne C, Fagius $J$ (1986) Skin nerve sympathetic activity during insulin induced hypoglycaemia. Diabetologia 29: 855-860

27. Bovill D (1973) A case of functional hypoglycaemia-a medicolegal problem. Br J Psychiatry 123: 353-358

28. Marks V (1981) Alcohol and hypoglycaemia. In: Marks V, Rose FC (eds) Hypoglycaemia. Blackwell, Oxford London, pp 387-398

Received: 27 June 1989

and in revised form: 1 November 1989

Dr. R. B. Tattersall

Department of Medicine (Diabetes)

C Floor, South Block

University Hospital

Nottingham, UK 